\title{
Gender, Obesity and Repeated Elevation of C-Reactive Protein: Data from the CARDIA Cohort
}

\author{
Shinya Ishii ${ }^{1 *}$, Arun S. Karlamangla ${ }^{2}$, Marcos Bote ${ }^{3}$, Michael R. Irwin ${ }^{4}$, David R. Jacobs, Jr ${ }^{5}$, Hyong \\ Jin $\mathrm{Cho}^{4}$, Teresa E. Seeman ${ }^{2}$
}

1 Department of Geriatric Medicine, University of Tokyo, Bunkyo-ku, Tokyo, Japan, 2 Division of Geriatrics, Department of Medicine, University of California Los Angeles, Los Angeles, California, United States of America, 3 Department of Sociology and Social Policy, University of Murcia, Murcia, Spain, 4 Cousins Center for Psychoneuroimmunology, Semel Institute for Neuroscience and Human Behavior, University of California Los Angeles, Los Angeles, California, United States of America, 5 Division of Epidemiology and Community Health, School of Public Health, University of Minnesota, Minneapolis, Minnesota, United States of America

\begin{abstract}
C-reactive Protein (CRP) measurements above $10 \mathrm{mg} / \mathrm{L}$ have been conventionally treated as acute inflammation and excluded from epidemiologic studies of chronic inflammation. However, recent evidence suggest that such CRP elevations can be seen even with chronic inflammation. The authors assessed 3,300 participants in The Coronary Artery Risk Development in Young Adults study, who had two or more CRP measurements between 1992/3 and 2005/6 to a) investigate characteristics associated with repeated CRP elevation above $10 \mathrm{mg} / \mathrm{L} ; \mathrm{b}$ ) identify subgroups at high risk of repeated elevation; and c) investigate the effect of different CRP thresholds on the probability of an elevation being onetime rather than repeated. 225 participants (6.8\%) had one-time and $103(3.1 \%)$ had repeated CRP elevation above $10 \mathrm{mg} / \mathrm{L}$. Repeated elevation was associated with obesity, female gender, low income, and sex hormone use. The probability of an elevation above $10 \mathrm{mg} / \mathrm{L}$ being one-time rather than repeated was lowest (51\%) in women with body mass index above $31 \mathrm{~kg} / \mathrm{m}^{2}$, compared to $82 \%$ in others. These findings suggest that CRP elevations above $10 \mathrm{mg} / \mathrm{L}$ in obese women are likely to be from chronic rather than acute inflammation, and that CRP thresholds above $10 \mathrm{mg} / \mathrm{L}$ may be warranted to distinguish acute from chronic inflammation in obese women.
\end{abstract}

Citation: Ishii S, Karlamangla AS, Bote M, Irwin MR, Jacobs DR Jr, et al. (2012) Gender, Obesity and Repeated Elevation of C-Reactive Protein: Data from the CARDIA Cohort. PLoS ONE 7(4): e36062. doi:10.1371/journal.pone.0036062

Editor: Stefan Kiechl, Innsbruck Medical University, Austria

Received March 3, 2012; Accepted March 30, 2012; Published April 30, 2012

Copyright: (C) 2012 Ishii et al. This is an open-access article distributed under the terms of the Creative Commons Attribution License, which permits unrestricted use, distribution, and reproduction in any medium, provided the original author and source are credited.

Funding: This work was supported by grant P30 AG028748, 5R01 AG26105-3 to A.K. and P30 AG017265 to T.E.S. from the National Institute on Aging of National Institutes of Health, and VA Greater Los Angeles Healthcare System Geriatric Research, Education and Clinical Center; and VA Advanced Geriatrics Fellowship to S.I. The funders had no role in study design, data collection and analysis, decision to publish, or preparation of the manuscript.

Competing Interests: The authors have declared that no competing interests exist.

*E-mail: sishii76@gmail.com

\section{Introduction}

With growing evidence linking chronic inflammation to various major disease processes, interest in C-Reactive Protein (CRP) - a robust marker of systemic inflammation - has increased sharply. Efforts to elucidate the role of CRP in cardiovascular and other disease processes have necessitated consideration of how to interpret very high levels of CRP, specifically whether values above a certain level (e.g., $10 \mathrm{mg} / \mathrm{L}$ ) reflect acute inflammation, such as due to recent or ongoing infection, and should therefore not be used as a marker of chronic inflammation. Clinical guidelines recommend repeat CRP measurement (after at least 2 weeks) in those with an initial reading $>10 \mathrm{mg} / \mathrm{L}$, to distinguish between short-term and more sustained elevation [1-3]. In research studies, the current convention is to exclude those with CRP $>10 \mathrm{mg} / \mathrm{L}$ [3]. However, there are multiple reasons to question the $10 \mathrm{mg} / \mathrm{L}$ threshold for distinguishing acute from chronic inflammation. First, CRP values greater than $10 \mathrm{mg} / \mathrm{L}$ are not uncommon; multiple studies indicate that $5 \%$ or more of the population has such values [4-7]. Second, some data suggest that even a one-time CRP value $>10 \mathrm{mg} / \mathrm{L}$ does have long-term health implications. Indeed, individuals with GRP $>10 \mathrm{mg} / \mathrm{L}$ had the highest risk of future vascular events in several cohorts, including healthy middle-aged women [4], middle-aged men and women [8], older men and women [9], and post-stroke patients [10]. Thus, CRP values $>10 \mathrm{mg} / \mathrm{L}$ might indicate chronic inflammation in a large proportion of individuals, and this may especially be so in people with characteristics such as obesity and smoking, which are known risk factors for chronic inflammation.

Accordingly, our objective was to determine what proportion of patients, among those who do not report being sick recently, have CRP $>10 \mathrm{mg} / \mathrm{L}$; whether this proportion varies by patient characteristics; whether these patients actually show evidence of sustained CRP elevation over several years; and if a higher threshold could be used to improve the identification of those with one-time elevation. The latter, if found, would have important implications for the current practice of treating CRP values over $10 \mathrm{mg} / \mathrm{L}$ as indicative of acute infection and excluding them from analyses. To the extent that we find that many CRP values over $10 \mathrm{mg} / \mathrm{L}$ are, in fact, more likely indicative of chronically high levels, exclusion of such values from analyses should be reconsidered.

\section{Methods}

Study Design and Population

The Coronary Artery Risk Development in Young Adults (CARDIA) is a bi-ethnic, prospective, multi-center study of the 
evolution of cardiovascular risk beginning in young adulthood. In 1985-1986, 5, 115 participants, aged 18 to 30 years, were recruited at Birmingham, AL; Chicago, IL; Minneapolis, MN; and Oakland, CA, to achieve a balance at each site by race (black, white), gender, education (high school degree or less, more than high school), and age (18-24 years, 25-30 years [11]). Follow-up examinations occurred during 1987-1988 (Year 2), 1990-1991 (Year 5), 1992-1993 (Year 7), 1995-1996 (Year 10), 2000-2001 (Year 15), and 2005-2006 (Year 20). A majority of the surviving group has been examined at each follow-up $(91 \%, 86 \%, 81 \%$, $79 \%, 74 \%$, and $72 \%$, respectively). Before exclusions (detailed below), 4,086 participants who were examined at year 7 were eligible for this analysis. Serum CRP measurements were made in Years 7, 15, and 20. CRP values of those reporting having been sick during the 24 hours preceding their blood draw were coded as missing for that year $-8.8 \%(n=355)$ for Year 7, 7.9\% $(n=266)$ for Year 15 and $5.6 \%(\mathrm{n}=179)$ for Year 20, for a total of 800 excluded CRP measurements. In total, 167 participants were completely excluded from the analysis because they reported having been sick at one or more than one visits. Inclusion in the present analyses required availability of valid CRP data (when not sick in the previous 24 hours) on at least two of the three visits in years 7,15 and $20(n=3,354)$. Those who were pregnant $(n=50)$ or had self-reported coronary artery disease $(n=4)$ at Year 7 were excluded, leaving a sample size of 3,300. The study was approved by an institutional review board at each CARDIA study site (Birmingham, AL; Chicago, IL; Minneapolis, MN; and Oakland, CA). All participants provided written informed consent at each examination. Detailed study design and cohort descriptions are available [12].

\section{Measurements: C-Reactive Protein}

Plasma CRP assays for all samples were done using the BNII nephelometer from Dade Behring utilizing a particle enhanced immunonepholometric assay; the assay range is $0.175-1,100 \mathrm{mg} /$ $\mathrm{L}$, intra-assay coefficients of variation $2.3-4.4 \%$ and inter-assay coefficients of variation 2.1-5.7\%. Technical error (including handling, storage, and assay variation) in blinded duplicate plasma aliquots at years 15 and 20 was $18.5 \%$ and $20.4 \%$, respectively.

We defined one-time CRP elevation as having CRP $>10 \mathrm{mg} / \mathrm{L}$ at exactly one visit, and repeated elevation as having CRP $>10 \mathrm{mg} / \mathrm{L}$ at two or more visits.

\section{Measurements: Predictors of CRP Elevation}

The predictors considered were participant characteristics at the initial CRP evaluation (Year 7), pre-specified based on literature review.

Socio-demographic variables examined were gender, race (AfricanAmerican vs. Caucasian), pre-tax family income (Less than 25,000 dollars a year; 25,000 to 50,$000 ; 50,000$ to 75,000 ; and more than 75,000 ), and highest education grade completed (High School or Less, College Only, or Graduate School).

Health Behavior variables. Smoking status was coded as never-smoker, past-smoker, and current-smoker. A physical activity intensity score was computed by multiplying reported frequency of engagement in 13 exercise and recreation activities by the intensity of the activity [13]. Consumption of wine, beer, and liquor was assessed and summed to create an index of total alcohol consumption (ml/day). The total alcohol consumption was then categorized as non-drinker, moderate-drinker $(0.1-12 \mathrm{ml} /$ day) or severe-drinker (>12 ml/day).

Health status. Participants were asked about doctordiagnosed high blood pressure, diabetes, high cholesterol, asthma, chronic obstructive pulmonary disease and cancer. Asthma and chronic obstructive pulmonary disease were combined into a binary variable, respiratory conditions. Information was also collected on medications for hypertension, aspirin, oral contraceptive pills and hormone replacement therapy. Use of oral contraceptive pills and hormone replacement therapy were combined into a binary variable, use of sex hormones. Body mass index (BMI) was calculated from measured height and weight.

\section{Analyses}

Analyses were undertaken to answer the following three questions:

1. What patient characteristics are associated with CRP elevation above $10 \mathrm{mg} / \mathrm{L}$ one or more times, relative to no CRP elevation above $10 \mathrm{mg} / \mathrm{L}$ ?

2. Of those with CRP elevated above $10 \mathrm{mg} / \mathrm{L}$ one or more times, are certain patient characteristics associated with greater likelihood of the CRP elevation being repeated rather than a one-time elevation?

3. Can we improve the identification of one-time CRP elevation by using different CRP thresholds in different groups?

First, the associations of socio-demographic, health status, and health behavior characteristics with the odds of CRP elevation above $10 \mathrm{mg} / \mathrm{L}$ one or more times (relative to no CRP elevation above $10 \mathrm{mg} / \mathrm{L}$ ) were examined using multinomial logistic regression. Physical activity, BMI and age were included as continuous variables; the rest as categorical. In addition, we included a quadratic term for BMI (BMI was centered at the mean and then squared) and two gender by variable interactions (i.e., gender by BMI and BMI-squared) based on literature review [5,7,14-20].

Second, we examined the odds of repeated CRP elevation among those who had at least one episode of CRP elevation above $10 \mathrm{mg} / \mathrm{L}$, as a function of the same demographic/health/lifestyle characteristics, using logistic regression. The model was made parsimonious using backward selection based on the Akaike Information Criterion [21]. A generalized Spearman correlation was used to identify the two most influential predictor variables in the logistic regression model [22]. Next, using the two most influential variables as predictors, regression tree analysis was performed to identify subgroups at high risk for CRP elevations being repeated rather than one-time elevations [23].

Finally, we examined the effects of various CRP thresholds on the probability of above-threshold elevations being one-time elevations in sub-groups defined by the two characteristics that were most influential in the logistic regression model.

Analyses used R statistical software version 2.9.0 (R Foundation, Vienna, Austria). All statistical tests were two-sided, and a $P$-value less than 0.05 was considered statistically significant.

\section{Results}

The study sample $(n=3,300)$ was representative of the complete CARDIA Year 7 sample $(n=4,086)$ with respect to clinical characteristics at baseline. In the study sample, 2,972 (90.1\%) had no episode of CRP elevation above $10 \mathrm{mg} / \mathrm{L}$, while $225(6.8 \%)$ had one-time elevation and $103(3.1 \%)$ had elevation on at least two occasions (Table 1). Among the 3,300 participants included, $471(14.3 \%)$ reported being sick at one visit, of whom $41(8.7 \%)$ had CRP elevation at one or more non-sick visits. The prevalence of CRP elevation above $10 \mathrm{mg} / \mathrm{L}$ did not increase from year 7 
$(4.3 \%)$ to year $20(3.7 \%)$. Of the 225 participants with one-time elevation above $10 \mathrm{mg} / \mathrm{L}$, only 60 (1.8\% of 3,300, $26.7 \%$ of 225$)$ had no other CRP readings above $3 \mathrm{mg} / \mathrm{L}$; the other $165 \mathrm{had}$ at least one other reading above $3 \mathrm{mg} / \mathrm{L}$, and 96 of them had at least one other reading above $6 \mathrm{mg} / \mathrm{L}$, suggesting chronic rather than acute inflammation.
Multinomial logistic regression of one-time and repeated CRP elevation (relative to no CRP elevation above $10 \mathrm{mg} / \mathrm{L}$ ) demonstrated that higher income was associated with decreased odds of repeated CRP elevation, and both current and past smoking were associated with increased odds of one-time CRP elevation. Women were more likely than men to have both one-

Table 1. Baseline (year 7) Characteristics of 3,300 Participants in the CARDIA Study, According to the C-reactive Protein (CRP) Categories $^{* \dagger}$.

\begin{tabular}{|c|c|c|c|}
\hline Characteristics & $\begin{array}{l}\text { No CRP elevation above } \\
10 \mathrm{mg} / \mathrm{L}\end{array}$ & One-time CRP elevation & Repeated CRP elevation \\
\hline & $\mathrm{N}=2972$ & $N=225$ & $\mathrm{~N}=103$ \\
\hline Age(years) & $33(29,35)$ & $33(30,35)$ & $32(29,35)$ \\
\hline \multicolumn{4}{|l|}{ Gender } \\
\hline male & 47.6 & 29.3 & 11.7 \\
\hline female & 52.4 & 70.7 & 88.4 \\
\hline \multicolumn{4}{|l|}{ Race } \\
\hline Caucasian & 56.0 & 40.4 & 24.3 \\
\hline African-American & 44.0 & 59.6 & 75.7 \\
\hline \multicolumn{4}{|l|}{ Income } \\
\hline$<\$ 25 \mathrm{~K} /$ year & 30.4 & 37.7 & 54.4 \\
\hline$\$ 25-\$ 50 \mathrm{~K} /$ year & 36.9 & 39.6 & 33.0 \\
\hline$\$ 50-\$ 75 \mathrm{~K} /$ year & 18.0 & 14.1 & 11.7 \\
\hline$>\$ 75 \mathrm{~K} /$ year & 14.8 & 8.6 & 1.0 \\
\hline \multicolumn{4}{|l|}{ Education } \\
\hline high school & 26.1 & 30.8 & 35.9 \\
\hline college & 54.1 & 52.9 & 55.3 \\
\hline graduate school & 19.9 & 16.3 & 8.7 \\
\hline \multicolumn{4}{|l|}{ Smoking status } \\
\hline current smoker & 24.2 & 30.7 & 29.4 \\
\hline former smoker & 15.8 & 20.0 & 12.8 \\
\hline Physical activity (100 EU) & $2.8(1.4,4.9)$ & $2.1(1.1,4.3)$ & $1.6(0.6,3.0)$ \\
\hline \multicolumn{4}{|l|}{ Alcohol use } \\
\hline non-drinker & 44.2 & 48.9 & 62.8 \\
\hline$<1$ glass a day & 28.2 & 24.9 & 17.7 \\
\hline$>=1$ glass a day & 27.6 & 26.2 & 19.6 \\
\hline Body mass index $\left(\mathrm{kg} / \mathrm{m}^{2}\right)$ & $25.1(22.4,28.6)$ & $29.1(25.4,34.8)$ & $35.8(30.8,41.5)$ \\
\hline \multicolumn{4}{|l|}{ Comorbidities $\S$} \\
\hline hypertension & 9.0 & 12.4 & 24.3 \\
\hline diabetes mellitus & 3.1 & 4.9 & 4.9 \\
\hline hyperlipidemia & 11.8 & 11.3 & 12.9 \\
\hline respiratory conditions $\|$ & 10.8 & 14.8 & 18.6 \\
\hline cancer & 1.9 & 2.7 & 0 \\
\hline \multicolumn{4}{|l|}{ Medication use } \\
\hline sex hormones & 22.5 & 28.3 & 24.2 \\
\hline aspirin & 3.5 & 3.6 & 1.9 \\
\hline anti-hypertensives & 1.4 & 2.2 & 4.9 \\
\hline
\end{tabular}

Abbreviations; $\mathrm{K}, 1,000$ : EU, exercise units:

* Median values and interquartile ranges are shown for continuous variables and percentages for categorical variables.

†Percentages may not add up to 100 because of rounding.

\$ 1 drink/day approximately corresponds to $12 \mathrm{~g}$ alcohol/day.

"Comorbidities were self-reported in response to the questions "Has a doctor or nurse ever told you that you have ...".

"Asthma and/or chronic obstructive pulmonary disease.

"Use of oral contraceptive pills or menopausal hormone replacement therapy. The percentages given in this row are among women only.

doi:10.1371/journal.pone.0036062.t001 
time and repeated CRP elevation, even after controlling for the use of sex hormones, which was also associated with increased odds of both one-time and repeated CRP elevation (Table 2). High BMI was associated with increased odds of both one-time and repeated CRP elevation, but the magnitude of the association was smaller in men than in women. In women, the odds of both onetime and repeated CRP elevation increased dramatically with BMI (Figure 1a). In fact, $69.9 \%$ of repeated elevations and $35.1 \%$ of one-time elevations were in obese women (with BMI $>30 \mathrm{~kg}$ / $\mathrm{m}^{2}$ ), although they represented only $14.6 \%$ of the study sample.

In the 328 participants who had at least one CRP elevation above $10 \mathrm{mg} / \mathrm{L}$, the proportion with a one-time elevation was only $68.6 \%$; nearly a third of those with CRP elevations above $10 \mathrm{mg} / \mathrm{L}$ had repeated elevations. Female gender, low income, hypertension, and high BMI were associated positively with the odds of CRP elevation being repeated, although the magnitude of the association with BMI was smaller in men than in women (Table 3 and Figure 1b). The most influential predictors in the model were BMI and gender: Their generalized Spearman correlation coefficients with the model-predicted log odds (the linear combination in the right hand side of the model) were 0.112 for BMI and 0.34 for gender; all other predictors had generalized Spearman correlations (with the model-predicted log odds) that were no greater than 0.24 .

Regression tree analysis was then used to identify subgroups with distinct risks for a CRP elevation being repeated, with the model-predicted log odds as the outcome and BMI and gender as predictors. (Figure 2) Three groups were identified: women with BMI $>31 \mathrm{~kg} / \mathrm{m}^{2}$ (highest risk), men with BMI $>22 \mathrm{~kg} / \mathrm{m}^{2}$ and women with BMI above $22 \mathrm{~kg} / \mathrm{m}^{2}$ but no more than $31 \mathrm{~kg} / \mathrm{m}^{2}$ (intermediate risk), and men and women with BMI $<=22 \mathrm{~kg} / \mathrm{m}^{2}$ (lowest risk). The probability that a CRP elevation is a one-time elevation was lowest, at $51 \%$, in the highest risk group (women with $\mathrm{BMI}>31 \mathrm{~kg} / \mathrm{m}^{2}$ ) compared to $82 \%$ in the rest of the cohort. Figure 3 depicts the probability of a CRP elevation being a onetime elevation (transient elevation probability) as a function of CRP threshold in the 3 risk groups defined by BMI and gender. For these "BMI-gender" defined groups, as Table 4 illustrates, there is considerable variability in the specific CRP thresholds needed to achieve a given level of transient elevation probability. In the intermediate-risk group, the probability that a CRP elevation is a one-time elevation is $80 \%$ at the usual threshold of $10 \mathrm{mg} / \mathrm{L}$, but in women with BMI $>31 \mathrm{~kg} / \mathrm{m}^{2}$, the probability that a CRP elevation is a one-time elevation was $80 \%$ only at the much higher threshold of $22 \mathrm{mg} / \mathrm{L}$.

\section{Discussion}

In the CARDIA study, the prevalence of elevated CRP values over $10 \mathrm{mg} / \mathrm{L}$ was $9.9 \%$, with approximately $3 \%$ of the sample showing repeated elevations over $10 \mathrm{mg} / \mathrm{L}$ over 13 years. Importantly, these prevalences were generated after excluding those who reported being sick in the 24 hours prior to measurement. Female gender, low income, high BMI, and the use of sex hormones were independently associated with increased odds of repeatedly elevated CRP, relative to no CRP elevation above $10 \mathrm{mg} / \mathrm{L}$. Previous studies of predictors of very high $(>10 \mathrm{mg} / \mathrm{L})$ CRP have not separated one-time CRP elevation from repeated elevation, but identified the same risk factors [5$7,24,25]$. Consistent with previous studies, we also found that the relationship between BMI and the odds of very high CRP (both one-time and repeated) was not linear and was modified by gender $[5,7,14,15]$. At higher levels of BMI in women, it appears that repeated CRP elevation is almost normative.

The major new finding from this study is that female gender, low income, high BMI and doctor-diagnosed hypertension, all
A

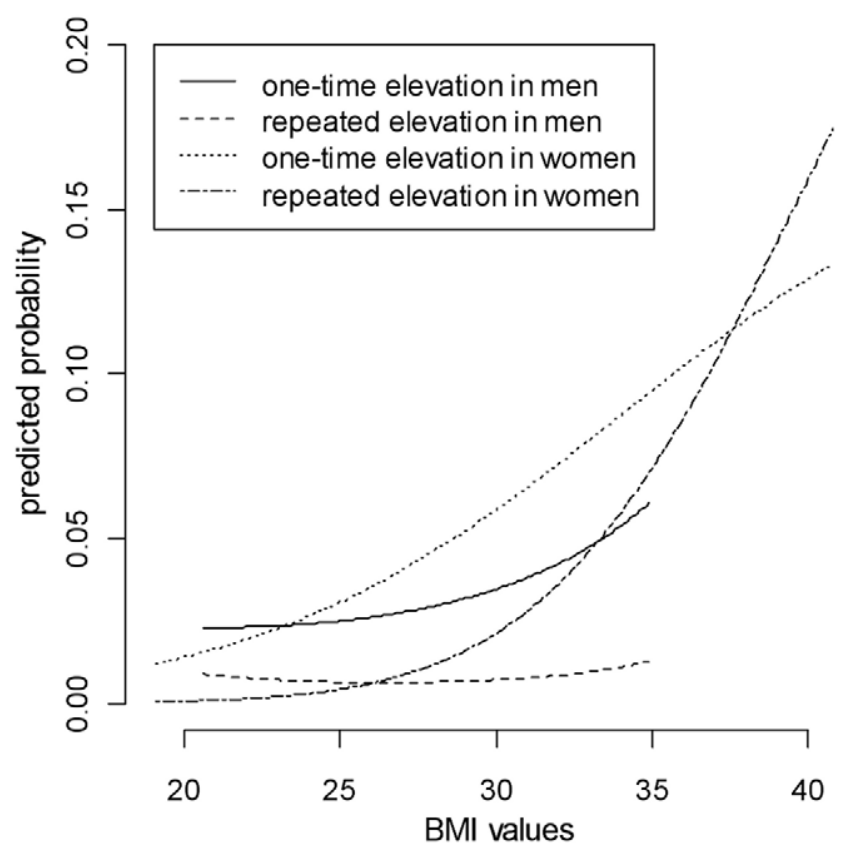

B

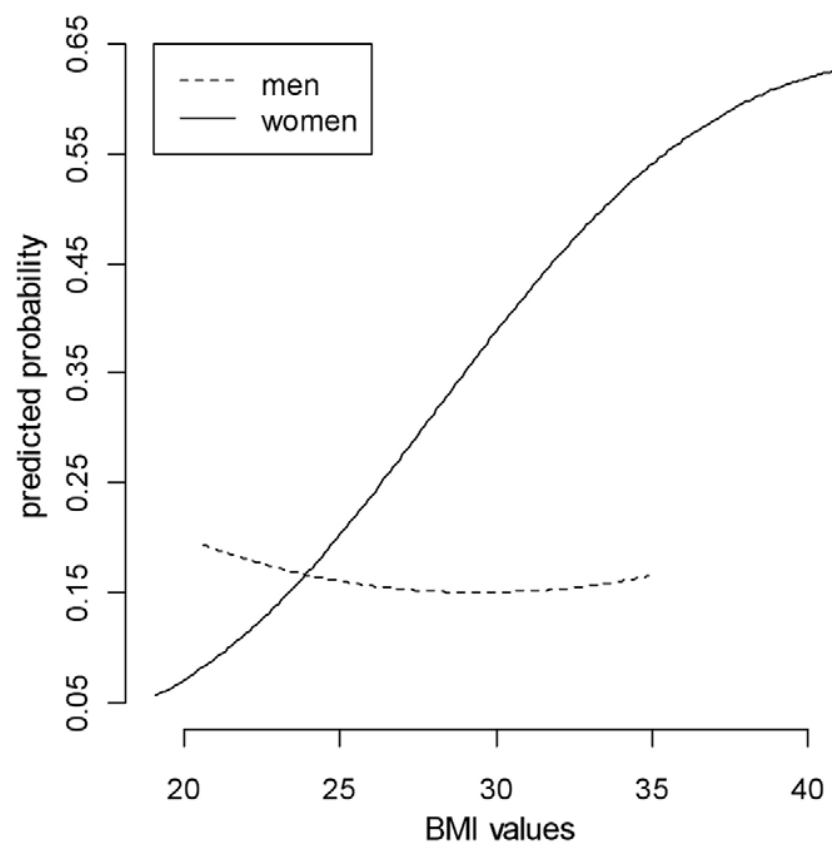

Figure 1. Predicted probabilities of C-Reactive Protein (CRP) elevation above $\mathbf{1 0} \mathbf{~ m g} / \mathrm{L}$ as function of body mass index (BMI). The predicted probabilities were computed from multiple logistic regression models while all other covariates were held constant (at reference values for categorical covariates and median values for continuous covariates). Panel A. Model-predicted probabilities of one-time and repeated CRP elevation. Panel B. Model-predicted probabilities of exactly one-time CRP elevation among those with one or more CRP elevations above $10 \mathrm{mg} / \mathrm{dL}$. doi:10.1371/journal.pone.0036062.g001 
Table 2. Multivariable-Adjusted Odds Ratio for C-Reactive Protein Elevations Above $10 \mathrm{mg} / \mathrm{L}^{\dagger}$

\begin{tabular}{|c|c|c|}
\hline Characteristics & $\begin{array}{l}\text { OR for one-time elevation above } \\
10 \mathrm{mg} / \mathrm{L}^{\dagger}\end{array}$ & $\begin{array}{l}\text { OR for repeated elevation above } \\
10 \mathrm{mg} / \mathrm{L}^{\dagger}\end{array}$ \\
\hline & $(95 \% \mathrm{Cl})$ & $(95 \% \mathrm{Cl})$ \\
\hline Age (per year) & $1.02(0.98,1.07)$ & $0.99(0.93,1.05)$ \\
\hline \multicolumn{3}{|l|}{ Gender (ref: female) } \\
\hline male & $0.47(0.32,0.71)^{* * *}$ & $0.29(0.12,0.70)^{* *}$ \\
\hline \multicolumn{3}{|l|}{ Race (ref: Caucasian) } \\
\hline African-American & $1.33(0.96,1.84)$ & $1.46(0.86,2.47)$ \\
\hline \multicolumn{3}{|l|}{ Income(ref: <25 K/year) } \\
\hline $25-50 \mathrm{~K} /$ year & $0.97(0.68,1.37)$ & $0.57(0.35,0.96)^{*}$ \\
\hline $50-75 \mathrm{~K} /$ year & $0.83(0.52,1.34)$ & $0.43(0.19,0.97)^{*}$ \\
\hline$>75 \mathrm{~K} /$ year & $0.72(0.40,1.29)$ & $0.11(0.01,0.89)^{*}$ \\
\hline \multicolumn{3}{|l|}{ Education(ref: high school) } \\
\hline college & $0.89(0.63,1.26)$ & $1.02(0.61,1.71)$ \\
\hline graduate school & $1.22(0.75,2.01)$ & $0.90(0.36,2.25)$ \\
\hline \multicolumn{3}{|l|}{ Smoking status (ref: never smoker) } \\
\hline current smoker & $1.49(1.03,2.17)^{*}$ & $1.26(0.72,2.23)$ \\
\hline former smoker & $1.56(1.05,2.32)^{*}$ & $0.88(0.44,1.75)$ \\
\hline Physical activity (per $100 \mathrm{EU}$ ) & $0.98(0.92,1.04)$ & $0.93(0.83,1.04)$ \\
\hline \multicolumn{3}{|l|}{ Alcohol(ref: non-drinker) } \\
\hline$<1$ glass a day & $0.89(0.62,1.30)$ & $0.78(0.43,1.42)$ \\
\hline$>1$ glass a day & $1.12(0.77,1.65)$ & $0.98(0.52,1.87)$ \\
\hline BMI $\left(\text { per } \mathrm{kg} / \mathrm{m}^{2}\right)^{\ddagger}$ & $1.14(1.09,1.18)^{* * *}$ & $1.35(1.25,1.45)^{* * *}$ \\
\hline BMI squared & $0.998(0.996,0.999)^{*}$ & $0.993(0.990,0.996)^{* * *}$ \\
\hline Male*BMI $\left(\text { per } \mathrm{kg} / \mathrm{m}^{2}\right)^{\star}$ 竞 & $0.94(0.87,1.02)$ & $0.76(0.65,0.89)^{* * *}$ \\
\hline Male*BMI-squared ${ }^{\ddagger}$ & $1.008(1.002,1.013)^{* *}$ & $1.017(1.009,1.026)^{* * *}$ \\
\hline \multicolumn{3}{|l|}{ Comorbidities } \\
\hline hypertension & $0.96(0.58,1.59)$ & $1.69(0.91,3.14)$ \\
\hline diabetes mellitus & $1.07(0.54,2.13)$ & $0.57(0.20,1.57)$ \\
\hline hyperlipidemia & $0.93(0.59,1.48)$ & $1.15(0.58,2.26)$ \\
\hline respiratory conditions & $1.27(0.83,1.95)$ & $1.39(0.75,2.56)$ \\
\hline cancer & $1.17(0.46,2.97)$ & $\S$ \\
\hline \multicolumn{3}{|l|}{ Medication use } \\
\hline sex hormones & $1.90(1.26,2.86)^{* *}$ & $2.43(1.34,4.43)^{* *}$ \\
\hline aspirin & $0.85(0.37,1.95)$ & $0.48(0.11,2.22)$ \\
\hline anti-hypertensives & $0.46(0.12,1.71)$ & $0.66(0.19,2.27)$ \\
\hline
\end{tabular}

Abbreviations; $\mathrm{K}, 1,000$ : $\mathrm{BMI}$, body-mass index: $\mathrm{OR}$, odds ratio: $\mathrm{Cl}$, confidence intervals: EU, exercise units:

$*^{* *},{ }^{* *}$ denotes significance at $5 \%, 1 \%, 0.1 \%$ level, respectively.

${ }^{\dagger}$ Multinomial logistic regression was used to calculate adjusted odds ratio, which is the ratio of odds of having either one-time or repeated CRP elevation ( $>10$ mg/L) relative to the odds of having no CRP elevation (reference group). All predictors were measured at the initial CRP evaluation visit.

${ }^{*} \mathrm{BMI}$ is centered at the overall sample mean (26.7).

${ }^{\S}$ There is no observation with history of cancer and repeated CRP elevation.

"Male*BMI denotes the interaction between male gender and BMl; male*BMI-squared is the interaction between male gender and the square of BMI.

doi:10.1371/journal.pone.0036062.t002

independently increased the odds of a CRP elevation being repeated rather than one-time, with the association with BMI being non-linear and different by gender. All these characteristics tend to persist over time, suggesting that repeated CRP elevation represent a result of chronic processes [26-29].

Low income and female gender are both associated with greater levels of perceived stress [30], and chronic stress is a risk factor for inflammation [31]. Hypertension may also serve as a marker for chronic stress [32], as does obesity [33]. In addition, adipose tissue is a known source of CRP in humans [34]. Chronic conditions such as osteoarthritis, even if subclinical, are more likely in obese persons and can lead to elevated CRP, apart from inflammation caused directly by adipose tissue metabolism.

There are several possible explanations for our finding of gender differences in the relationship between high BMI and repeated GRP elevation. Higher estrogen levels may partly account for higher CRP levels in women, since this and previous studies have shown that exogenous estrogen therapy increases CRP levels $[35,36]$. Estrogen levels are also positively associated with BMI in women [37]. Obesity is associated with greater susceptibility to 
Table 3. Multivariable-Adjusted Odds Ratio for Repeated CRP Elevation Above $10 \mathrm{mg} / \mathrm{L}$ Among Those With at Least one CRP Elevation Above $10 \mathrm{mg} / \mathrm{L}^{*}$.

\begin{tabular}{|c|c|c|c|}
\hline Characteristics & & OR $(95 \% \mathrm{CI})$ & $P$ value \\
\hline Male & & $0.21(0.07,0.57)$ & .002 \\
\hline \multicolumn{4}{|c|}{ Income (ref: <25 K/year) } \\
\hline & $25 \mathrm{~K}-50 \mathrm{~K} /$ year & $0.58(0.32,1.03)$ & 0.06 \\
\hline & $50 \mathrm{~K}-75 \mathrm{~K} /$ year & $0.45(0.18,1.10)$ & 0.08 \\
\hline & $>75 \mathrm{~K} /$ year & $0.09(0.01,0.80)$ & 0.03 \\
\hline Hypertension & & $2.26(1.09,4.65)$ & 0.03 \\
\hline BMI $\left(\mathrm{kg} / \mathrm{m}^{2}\right)^{\dagger}$ & & $1.13(1.07,1.19)$ & $<.001$ \\
\hline Male*BMI ${ }^{\dagger *}$ & & $0.904(0.819,0.997)$ & 0.04 \\
\hline BMI squared ${ }^{\dagger}$ & & $0.994(0.990,0.998)$ & 0.002 \\
\hline Male*BMI-squared $^{\dagger *}$ & & $1.010(1.002,1.018)$ & 0.02 \\
\hline \multicolumn{4}{|c|}{$\begin{array}{l}\text { Abbreviations; } \mathrm{K}, 1,000 \text { : } \mathrm{BMI} \text {, body-mass index: OR, odds ratio: } \mathrm{Cl} \text {, confidence } \\
\text { intervals: } \\
{ }^{*} \text { Multiple logistic regression was used to calculate the adjusted odds ratios. } \\
{ }^{\dagger} \mathrm{BMI} \text { is centered at the mean ( } 32.4 \text { ) of those with at least one } \mathrm{CRP} \text { elevation. } \\
{ }^{\ddagger} \text { Male*BMI denotes the interaction between male gender and } \mathrm{BMI} \text {; male*BMI- } \\
\text { squared is the interaction between male gender and the square of BMI. } \\
\text { doi:10.1371/journal.pone. } 0036062.003\end{array}$} \\
\hline
\end{tabular}

infections [38], and therefore obesity-associated increase in frequency of infection may contribute to obesity-associated recurring increases in CRP. Whether there is any gender difference in obesity-associated susceptibility to infection warrants further research. Leptin, a hormone produced by adipose tissue, is higher in women compared with men, which may mediate some of the sex differences in the obesity-inflammation association [14,39]. Gender differences in fat distribution, such as the greater accumulation of subcutaneous fat in women than in men which partially accounts for gender differences in CRP levels [40], may also play a role.

This study also demonstrated that the probability of a CRP measurement above $10 \mathrm{mg} / \mathrm{L}$ being one-time (transient) elevation varied significantly across subgroups, with the transient elevation probability being lowest (only 51\%) in obese women (with BMI $>31 \mathrm{~kg} / \mathrm{m}^{2}$ ). To get transient elevation probabilities of $80 \%$, the CRP threshold should be $22 \mathrm{mg} / \mathrm{L}$ in obese women.

Our study has some note-worthy limitations. First, GRP measurements were excluded in those who reported having been sick during the 24 hours preceding their blood draw; but since CRP levels stay elevated for 7 to 12 days after an acute inflammatory condition [41], the 24-hour look-back period may not be sufficient. However, under $2 \%$ of the analytic sample had acute inflammation (with one CRP measurement above $10 \mathrm{mg} / \mathrm{L}$ and others $3 \mathrm{mg} / \mathrm{L}$ or lower), suggesting that the 24-hour retrospective report excluded most individuals with acute inflammation. Second, we did not account for the temporal ordering of CRP measurements in our analyses, which leaves open the possibility that an isolated CRP elevation in year 20 represents new-onset chronic inflammation, not transient acute CRP elevation. But, the prevalence of CRP elevation above $10 \mathrm{mg} / \mathrm{L}$ did not increase with age (see table 1 and 2) or time/year. In addition, among those with CRP $>10 \mathrm{mg} / \mathrm{L}$ in year 20 , the proportion with repeated elevation was comparable to that in years 7 and 15 (data not shown), suggesting that we are not underestimating persistence of CRP elevation in year 20. Third, repeatedly elevated measurements of CRP could, in some participants, represent recurring acute inflammation rather than chronic inflammation; we could not distinguish between the two from three CRP measurements spread out over 13 years, and discounted the possibility of recurring acute inflammation. It should be noted however, that the risk factors identified here, namely, female gender, low income, high BMI and doctordiagnosed hypertension may be associated with recurring acute inflammation rather than chronic inflammation - a question that requires considerably more detailed longitudinal data than are currently available through CARDIA. Lastly technical error in CRP measurement was fairly large in the study; while this could have led to some spurious elevations above $10 \mathrm{mg} / \mathrm{L}$, it is unlikely that a person whose true value was several $\mathrm{mg} / \mathrm{L}$ lower than 10 would have an observed value $>10 \mathrm{mg} / \mathrm{L}$.

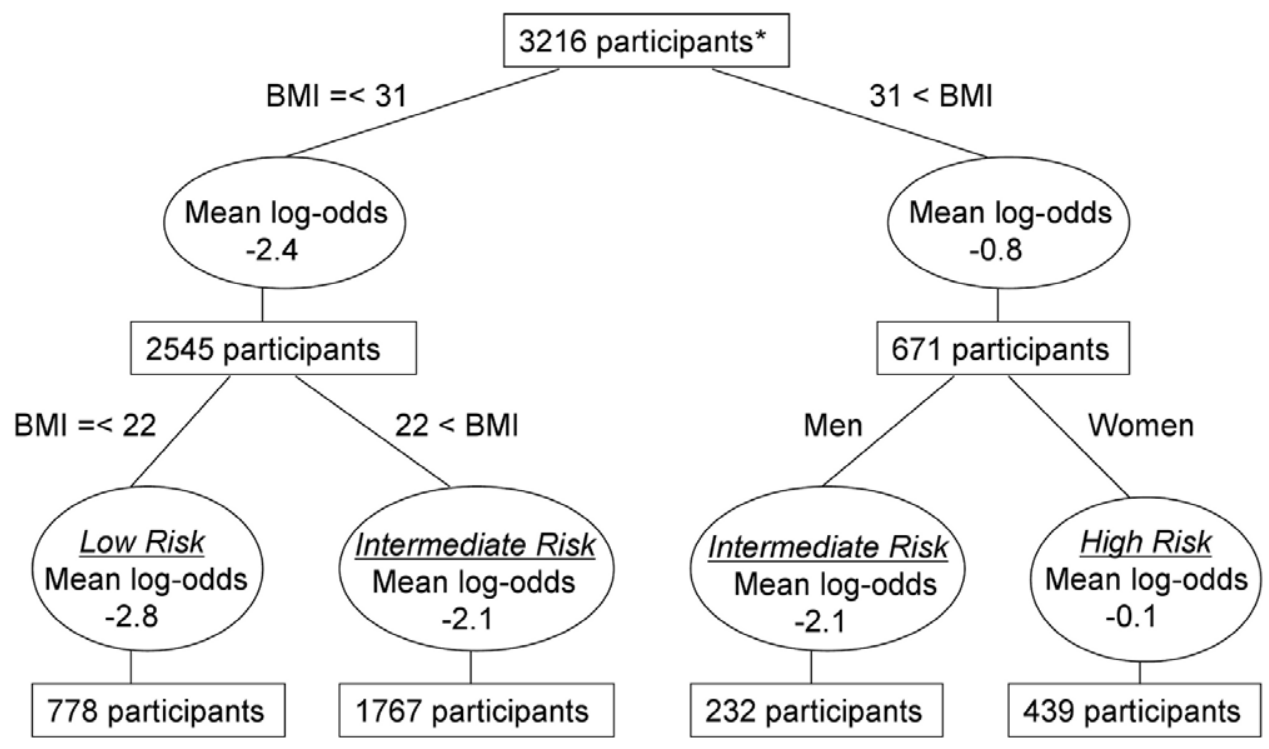

Figure 2. Risk stratification by baseline body mass index (BMI) and gender. Regression tree analysis was performed for the log odds of a CRP elevation being repeated (as predicted by the logistic regression model) with BMI and gender as predictors. doi:10.1371/journal.pone.0036062.g002 


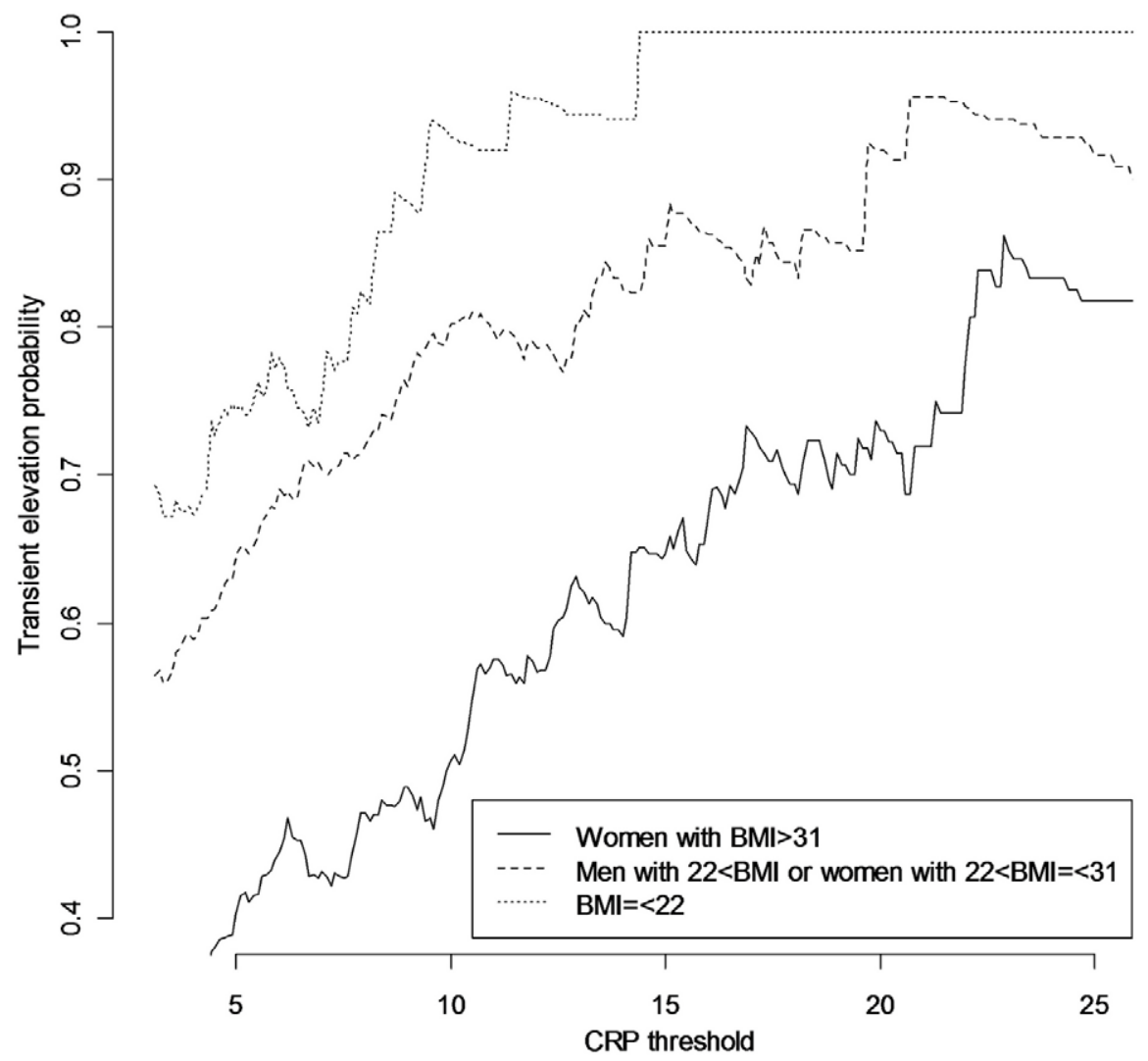

Figure 3. Probability of above-threshold CRP elevations being transient (one-time elevations), as function of CRP threshold. Probabilities in strata defined by gender and body mass index (BMI) were shown.

doi:10.1371/journal.pone.0036062.g003

Despite these limitations, our results have important implications for both clinical uses of CRP and epidemiological and clinical research studies on CRP. We have made several novel findings. We demonstrated that a significant proportion of people who do not report being sick (in the last 24 hours) have levels of CRP over $10 \mathrm{mg} / \mathrm{L}$, which persist (or are at least, recurring) over 13 years. While our results are confirmatory that female gender, high BMI, sex hormone use and low income are chronic factors that are associated with CRP over $10 \mathrm{mg} / \mathrm{L}$ at a single cross-sectional timepoint, we also find that these chronic factors contribute to persistent elevated levels of CRP. These findings suggest that the current convention in research studies of excluding anyone with
CRP $>10 \mathrm{mg} / \mathrm{L}$ likely excludes many with chronic inflammation who are at the highest risk for poor health outcomes, and likely introduces bias into study findings.

We propose that epidemiologic studies that rely on a single measurement of CRP should not automatically discount all measurements above $10 \mathrm{mg} / \mathrm{L}$ as indicators of acute inflammation. Ideally, CRP should be measured repeatedly. If repeated measurements are not feasible and only a one-time measurement of CRP is available, participant-specific thresholds may be called for. In particular, a CRP threshold higher than $10 \mathrm{mg} / \mathrm{L}$ is needed to distinguish acute from chronic inflammation in obese women.

Table 4. CRP Thresholds (in $\mathrm{mg} / \mathrm{L}$ ) Required to Achieve Varying Probabilities of Above-Threshold Elevations Being One-Time (Transient Elevation Probabilities) in Sub-Groups Defined by BMI and Gender.

\begin{tabular}{|c|c|c|c|}
\hline $\begin{array}{l}\text { Desired transient } \\
\text { elevation probability }\end{array}$ & $\begin{array}{l}\text { CRP threshold needed in } \\
\text { low-risk group (BMI } \leq 22 \mathrm{~kg} / \mathrm{m} 2)\end{array}$ & $\begin{array}{l}\text { CRP threshold needed in intermediate-risk } \\
\text { group (Men with BMI >22 and women } \\
\text { with BMI }>22 \text { and } \leq 31 \mathrm{~kg} / \mathrm{m} 2 \text { ) }\end{array}$ & $\begin{array}{l}\text { CRP threshold needed in high-risk } \\
\text { group (Women with BMI >31 kg/m2) }\end{array}$ \\
\hline $70 \%$ & 4.4 & 6.5 & 16.8 \\
\hline $75 \%$ & 5.4 & 8.8 & 21.3 \\
\hline $80 \%$ & 7.7 & 10.0 & 22.1 \\
\hline $85 \%$ & 8.3 & 14.6 & 22.9 \\
\hline $90 \%$ & 9.4 & 19.7 & 27.8 \\
\hline $95 \%$ & 11.4 & 20.7 & 42.7 \\
\hline
\end{tabular}

doi:10.1371/journal.pone.0036062.t004 


\section{Author Contributions}

Conceived and designed the experiments: SI AK MB MI HJC TS. Analyzed the data: SI AK DJ TS. Contributed reagents/materials/analysis

\section{References}

1. Pearson TA, Mensah GA, Alexander RW, Anderson JL, Cannon RO, 3rd, et al. (2003) Markers of inflammation and cardiovascular disease: application to clinical and public health practice: A statement for healthcare professionals from the Centers for Disease Control and Prevention and the American Heart Association. Circulation 107: 499-511.

2. Myers GL, Rifai N, Tracy RP, Roberts WL, Alexander RW, et al. (2004) CDC/ AHA Workshop on Markers of Inflammation and Cardiovascular Disease: Application to Clinical and Public Health Practice: report from the laboratory science discussion group. Circulation 110: e545-549.

3. Ridker PM (2003) Clinical application of C-reactive protein for cardiovascular disease detection and prevention. Circulation 107: 363-369.

4. Ridker PM, Cook N (2004) Clinical usefulness of very high and very low levels of C-reactive protein across the full range of Framingham Risk Scores. Circulation 109: 1955-1959.

5. Visser M, Bouter LM, McQuillan GM, Wener MH, Harris TB (1999) Elevated C-reactive protein levels in overweight and obese adults. Jama 282: 2131-2135.

6. Alley DE, Seeman TE, Ki Kim J, Karlamangla A, Hu P, et al. (2006) Socioeconomic status and C-reactive protein levels in the US population: NHANES IV. Brain Behav Immun 20: 498-504.

7. Nazmi A, Oliveira IO, Victora GG (2008) Correlates of C-reactive protein levels in young adults: a population-based cohort study of 3827 subjects in Brazil. Braz J Med Biol Res 41: 357-367.

8. Hamer M, Chida Y, Stamatakis E (2009) Association of very highly elevated Creactive protein concentration with cardiovascular events and all-cause mortality. Clin Chem 56: 132-135.

9. Cushman M, Arnold AM, Psaty BM, Manolio TA, Kuller LH, et al. (2005) Creactive protein and the 10-year incidence of coronary heart disease in older men and women: the cardiovascular health study. Circulation 112: 25-31.

10. Muir KW, Weir CJ, Alwan W, Squire IB, Lees KR (1999) C-reactive protein and outcome after ischemic stroke. Stroke 30: 981-985.

11. Cutter GR, Burke GL, Dyer AR, Friedman GD, Hilner JE, et al. (1991) Cardiovascular risk factors in young adults. The CARDIA baseline monograph. Control Clin Trials 12: 1S-77S

12. Friedman GD, Cutter GR, Donahue RP, Hughes GH, Hulley SB, et al. (1988) CARDIA: study design, recruitment, and some characteristics of the examined subjects. J Clin Epidemiol 41: 1105-1116.

13. Sidney S, Jacobs DR, Jr., Haskell WL, Armstrong MA, Dimicco A, et al. (1991) Comparison of two methods of assessing physical activity in the Coronary Artery Risk Development in Young Adults (CARDIA) Study. Am J Epidemiol 133: 1231-1245.

14. Khera A, Vega GL, Das SR, Ayers C, McGuire DK, et al. (2009) Sex differences in the relationship between C-reactive protein and body fat. J Clin Endocrinol Metab 94: 3251-3258.

15. Chenillot O, Henny J, Steinmetz J, Herbeth B, Wagner C, et al. (2000) High sensitivity C-reactive protein: biological variations and reference limits. Clin Chem Lab Med 38: 1003-1011.

16. O'Connor MF, Bower JE, Cho HJ, Creswell JD, Dimitrov S, et al. (2009) To assess, to control, to exclude: effects of biobehavioral factors on circulating inflammatory markers. Brain Behav Immun 23: 887-897.

17. Ray KK, Cannon CP, Cairns R, Morrow DA, Rifai N, et al. (2005) Relationship between uncontrolled risk factors and C-reactive protein levels in patients receiving standard or intensive statin therapy for acute coronary syndromes in the PROVE IT-TIMI 22 trial. J Am Coll Cardiol 46: 1417-1424.

18. Groblewska M, Mroczko B, Wereszczynska-Siemiatkowska U, Kedra B, Lukaszewicz M, et al. (2008) Serum interleukin 6 (IL-6) and C-reactive protein (CRP) levels in colorectal adenoma and cancer patients. Clin Chem Lab Med 46: $1423-1428$.

19. Siemes C, Visser LE, Coebergh JW, Splinter TA, Witteman JC, et al. (2006) Creactive protein levels, variation in the $\mathrm{C}$-reactive protein gene, and cancer risk: the Rotterdam Study. J Clin Oncol 24: 5216-5222.

20. Heikkila K, Ebrahim S, Lawlor DA (2007) A systematic review of the association between circulating concentrations of $\mathrm{C}$ reactive protein and cancer. J Epidemiol Community Health 61: 824-833. tools: AK TS DJ. Wrote the paper: SI. Critical revision of the manuscript for important intellectual content: SI AK MB MI DJ HJC TS.

21. Hastie T, Tibshirani R, Friedman J (2009) The Elements of Statistical Learning: Data Mining, Inference, and Prediction. New York, NY: Springer.

22. Harrell FE (2001) Regression Modeling Strategies : With Applications to Linear Models, Logistic Regression, and Survival Analysis. New York, NY: Springer.

23. Izenman AJ (2008) Modern Multivariate Statistical Techniques : Regression, Classification, Manifold Learning. New York, NY: Springer.

24. Bazzano LA, He J, Muntner P, Vupputuri S, Whelton PK (2003) Relationship between cigarette smoking and novel risk factors for cardiovascular disease in the United States. Ann Intern Med 138: 891-897.

25. Greenfield JR, Samaras K, Jenkins AB, Kelly PJ, Spector TD, et al. (2004) Obesity is an important determinant of baseline serum C-reactive protein concentration in monozygotic twins, independent of genetic influences. Circulation 109: 3022-3028.

26. Lloyd-Jones DM, Liu K, Colangelo LA, Yan LL, Klein L, et al. (2007) Consistently stable or decreased body mass index in young adulthood and longitudinal changes in metabolic syndrome components: the Coronary Artery Risk Development in Young Adults Study. Circulation 115: 1004-1011.

27. Chobanian AV, Bakris GL, Black HR, Cushman WC, Green LA, et al. (2003) The Seventh Report of the Joint National Committee on Prevention, Detection, Evaluation, and Treatment of High Blood Pressure: the JNC 7 report. Jama 289: 2560-2572.

28. Rodgers JR, Rodgers JL (1993) Chronic Poverty in the United States. The Journal of Human Resources 28: 25-54.

29. Karlamangla AS, Singer BH, Williams DR, Schwartz JE, Matthews KA, et al. (2005) Impact of socioeconomic status on longitudinal accumulation of cardiovascular risk in young adults: the CARDIA Study (USA). Soc Sci Med 60: 999-1015

30. Macintyre S, Hunt K (1997) Socio-economic Position, Gender and Health: How Do They Interact? J Health Psychol 2: 315-334.

31. Black PH (2003) The inflammatory response is an integral part of the stress response: Implications for atherosclerosis, insulin resistance, type II diabetes and metabolic syndrome X. Brain Behav Immun 17: 350-364.

32. Goldstein DS (1995) Stress, Catecholamines, and Cardiovascular Disease: Oxford University Press.

33. Bjorntorp P (2001) Do stress reactions cause abdominal obesity and comorbidities? Obes Rev 2: 73-86.

34. Calabro P, Chang DW, Willerson JT, Yeh ET (2005) Release of C-reactive protein in response to inflammatory cytokines by human adipocytes: linking obesity to vascular inflammation. J Am Coll Cardiol 46: 1112-1113.

35. Lakoski SG, Brosnihan B, Herrington DM (2005) Hormone therapy, C-reactive protein, and progression of atherosclerosis: data from the Estrogen Replacement on Progression of Coronary Artery Atherosclerosis (ERA) trial. Am Heart J 150: 907-911.

36. Hu P, Greendale GA, Palla SL, Reboussin BA, Herrington DM, et al. (2006) The effects of hormone therapy on the markers of inflammation and endothelial function and plasma matrix metalloproteinase-9 level in postmenopausal women: the postmenopausal estrogen progestin intervention (PEPI) trial. Atherosclerosis 185: 347-352.

37. Lukanova A, Lundin E, Zeleniuch-Jacquotte A, Muti P, Mure A, et al. (2004) Body mass index, circulating levels of sex-steroid hormones, IGF-I and IGFbinding protein-3: a cross-sectional study in healthy women. Eur J Endocrinol 150: $161-171$.

38. Falagas ME, Kompoti M (2006) Obesity and infection. Lancet Infect Dis 6: 438-446.

39. Ruhl CE, Everhart JE, Ding J, Goodpaster BH, Kanaya AM, et al. (2004) Serum leptin concentrations and body adipose measures in older black and white adults. Am J Clin Nutr 80: 576-583.

40. Cartier A, Cote M, Lemieux I, Perusse L, Tremblay A, et al. (2009) Sex differences in inflammatory markers: what is the contribution of visceral adiposity? Am J Clin Nutr 89: 1307-1314.

41. Gabay C, Kushner I (1999) Acute-phase proteins and other systemic responses to inflammation. N Engl J Med 340: 448-454. 